\title{
BMJ Open COPAHS Study: protocol of a randomised experimental study comparing the effects of hypnosis, mindfulness meditation, and spiritual practices on experimental pain in healthy adults
}

Alexandra Ferreira-Valente (10) ${ }^{1,2}$ Filipa Pimenta, ${ }^{1}$ Rui M. Costa, ${ }^{1}$ Melissa A. Day, ${ }^{3}$ José Pais-Ribeiro, ${ }^{1}$ Mark P. Jensen ${ }^{2}$

To cite: Ferreira-Valente A, Pimenta F, Costa RM, et al. COPAHS Study: protocol of a randomised experimental study comparing the effects of hypnosis, mindfulness meditation, and spiritual practices on experimental pain in healthy adults. BMJ Open 2021;11:e040068. doi:10.1136/ bmjopen-2020-040068

- Prepublication history for this paper is available online. To view these files, please visit the journal online (http://dx.doi org/10.1136/bmjopen-2020040068).

Received 06 May 2020 Revised 23 November 2020 Accepted 21 January 2021

Check for updates

(c) Author(s) (or their employer(s)) 2021. Re-use permitted under CC BY-NC. No commercial re-use. See rights and permissions. Published by BMJ.

${ }^{1}$ William James Center for Research, ISPA - University Institute, Lisbon, Portugal ${ }^{2}$ Department of Rehabilitation Medicine, University of Washington, Seattle, Washington, USA

${ }^{3}$ The University of Queensland, School of Psychology, Saint Lucia, Queensland, Australia

Correspondence to Dr Alexandra Ferreira-Valente; mafvalente@gmail.com

\section{ABSTRACT}

Background There has been an increasing interest in studying the potential benefits of so-called complementary and alternative approaches for pain management, such as hypnosis and mindfulness-based interventions. More recently, researchers have been interested in studying the effects of spiritual practices on pain experience as well. These practices may increase pain tolerance, result in a positive re-appraisal of pain and influence other psychological variables that are known to be associated with pain experience. The purpose of this study is to evaluate and compare the immediate effects of self-hypnosis, mindfulness meditation, and a spiritual intervention relative to a control condition for increasing pain tolerance and reducing pain intensity and pain-related stress, in response to experimental painful stimulation. Methods and analysis Recruitment is anticipated to start in November 2020. This is a randomised quantitative experimental mixed-design repeated-measures study with three assessment points: baseline (T0), pre-test (T1) and post-test (T2). Eligible healthy adults will be randomised to one of the four study conditions. Interventions will be a 20-minute audio-guided practice of either self-hypnosis, mindfulness meditation, or Christian prayer. Participants in the control group will not be instructed to use any specific strategy during the painful stimulation. Participants will be submitted to a first cycle of Cold Pressor Arm Wrap. They will then listen to a 20 -minute audio recording inducing one of the three interventions, or, in the case of the control group, to a 20-minute audio recording of text from a natural history textbook. Primary outcomes are pain intensity and pain tolerance. Pain-related stress as measured by salivary cortisol level and heart rate variability are secondary outcomes.

Ethics and dissemination This study was approved by ISPA_University Institute's internal Ethics Committee for Research on 3rd December 2018 (reference $\mathrm{I} / 010 / 12 / 2018)$. Findings will be published in peerreviewed indexed journals and presented at conferences. Trial registration number ClinicalTrials.gov registry (NCT04491630). Stage: pre-results.
Strengths and limitations of this study

- This is an innovative study comparing the effects of three 20-minute interventions (self-hypnosis, mindful meditation, Christian prayer) relative to a control group of healthy participants experiencing experimentally induced pain.

- Standard Protocol Items Recommendations for Interventional Trials and Consolidated Standards of Reporting Trials checklist guidelines were followed, to ensure quality in all aspects of study planning, execution and reporting.

- Strengths of the study include the random allocation and specific efforts to limit bias (blinded outcome assessment, standardisation of intervention and collection of concomitant treatment).

- The primary limitation of this study is the limited generalisability of potential findings to populations with chronic pain and experiencing acute pain in natural context.

\section{INTRODUCTION}

Background and rationale

Pain is a universal experience. ${ }^{1}$ It is also a homeostatic and adaptive mechanism, essential for survival. ${ }^{2-4}$ Without pain, an injury or serious health condition could go unnoticed, potentially leading to the death of the organism. ${ }^{56}$

At the same time, pain is also an unpleasant and distressing experience that can undermine well-being, ${ }^{78}$ and is a primary reason for seeking medical care. ${ }^{9}$ Although minor acute pain can be readily managed, moderate-tosevere acute pain may require a level of care that may not be available in many treatment settings. ${ }^{10}$ Even when standard treatments are available, a large number of patients 
continue to report severe acute pain. ${ }^{11}{ }^{12}$ Relatedly, about $20 \%$ of patients with acute pain are not satisfied with the pain treatment provided to them. ${ }^{13}$ If not appropriately treated, severe acute pain is known to contribute to negative cardiovascular, immunological, gastrointestinal, renal, muscular, sleep and psychological complications. ${ }^{1014}$ The presence of severe acute pain also puts patients at risk for the development of chronic pain. ${ }^{10} 14$ All of this evidence supports the importance of patient access to effective acute pain management treatments.

Given its subjective and complex nature, effective pain management frequently requires more than analgesics. ${ }^{14}$ Pain is a multidimensional experience that cannot be merely explained by the physiological mechanisms that underline its experience. ${ }^{315} 16$ Pain is influenced by a number of biological (eg, physiological aetiology, severity of physical damage), psychological (eg, pain-related beliefs and pain coping responses), social (eg, social support) and spiritual/religious (eg, meaning in life, religiosity) factors. ${ }^{17-25}$ Not surprisingly, multidisciplinary treatment programmes that address the multifaceted nature of pain, including its psychosocial dimensions, are more effective than unimodal treatments that focus only on biomedical factors. ${ }^{26-28}$ Given this evidence, multidisciplinary treatments that include instruction and encouragement in the use of psychological, social and spiritual coping may be useful. ${ }^{1429}$

Two psychological coping responses that are commonly taught in such programmes are self-hypnosis $(\mathrm{SH})$ and mindfulness meditation (MM). Both SH and MM have evidence supporting their efficacy with acute, chronic and experimentally induced pain. ${ }^{30-40}$ Both interventions can be used independently or together, and have been shown to: (a) induce brain states that are hypothesised to be associated with a decrease in the processing of nociceptive input as well as adaptive cognitive processes such as acceptance and openness to suggestion; and (b) affect pain-related cognitive content-such as pain-related beliefs and cognitive pain coping responses. ${ }^{3738} 4041$ Both SH and MM have also been shown to have weak-to-strong effects on pain intensity and on pain tolerance, ${ }^{31} 32353839$ with the magnitude of the effects varying as a function of: (a) previous experience in using either of these strategies (being a novice vs being a long-term practitioner of MM); (b) outcome expectancies; (c) hypnotic suggestibility (for $\mathrm{SH}$ ), (d) trait absorption and (e) pretreatment (pain) acceptance. $.^{38} 40-44$ It is also possible that, as Tang et al have hypothesised, ${ }^{45}$ dispositional or baseline mindfulness-that is, a long-lasting and pre-existent tendency towards mindfulness of consciousness-affects brain processing, the ability to practice MM, as well as the effects of MM. In support of this hypothesis, a recent study examined the moderation effect of baseline mindfulness on the effects of MM, cognitive therapy and mindfulnessbased cognitive therapy for chronic low back pain. ${ }^{46}$ The authors found that non-reactivity (ie, a facet of baseline mindfulness that refers to active detachment from negative emotions and thoughts), but not observation (ie, a facet of baseline mindfulness that refers to how one sees, feels, and perceives the internal and external world around oneself and selects the stimuli requiring one's attention), moderated the effects of both MM and mindfulness-based cognitive therapy. Those participants with lower baseline non-reactivity reported greater improvement in physical function as a result of MM, while those with higher baseline non-reactivity reported greater improvement in mindfulness-based cognitive therapy. However, we are not aware of any other studies that have examined the moderating role of baseline mindfulness on the effects of MM.

Recent research on the role that spirituality (the extent to which an individual searches for meaning and purpose in life, as well as feelings of transcendence and of being connected to a higher power $)^{20}$ and religiosity (the degree of an individual's engagement with the belief system and with individual and group practices of a given religion $)^{20}$ - have on pain experience suggests that at least some individuals spontaneously engage in spiritual and religious practices when experiencing pain as a way to cope ${ }^{47-49}$ Moreover, higher levels of spirituality and religiosity $(\mathrm{S} / \mathrm{R})$ are hypothesised to have a buffering effect against stressors. ${ }^{47051}$ Both spiritual (eg, spirituality-based meditation) and religious practices (eg, prayer) that might reduce stress may account for these buffering effects. ${ }^{50}$ Although there is a growing interest in evaluating the potential benefits of spiritual and religious practices on pain experience, ${ }^{52-57}$ and on identifying the mechanisms that explain their buffering effects on pain experience, ${ }^{58}$ to date, only a limited number of studies have focused on these issues. This is especially true for religiosity and for religious practices. Findings from the limited number of studies that have been conducted suggest that $\mathrm{S} / \mathrm{R}$ and spiritual and religious practices may play a role in influencing pain (eg, pain tolerance and pain intensity) and pain-related outcomes (eg, painrelated distress). ${ }^{19} 20475054-56$ 59-61 These practices are thought to increase pain tolerance, determine a positive re-appraisal of pain and modulate psychosocial variables (eg, meaning of pain, beliefs and attributions, coping and mood) that are associated with pain experience. ${ }^{22} 476062$

However, these studies have focused primarily on clinical populations with chronic pain. There are only limited findings regarding the effects of $S / R$ and religious practices, such as Christian prayer (CP), on acute pain. ${ }^{5763}$ One of the few studies examining the effects of being or not being religious and of religious practices on acute experimentally induced pain was conducted by Wiech et $a l .{ }^{57}$ These authors presented a group of 12 practising Christian Catholics and a group of 12 self-described nonreligious participants to either a religious stimulus (ie, looking at an image of the Virgin Mary) or a non-religious stimulus (ie, looking at a matched image without religious connotation). Statistically significant and large condition and Group X Condition interaction effects were found, suggesting that the religious practice of contemplating a religious image has an effect on pain intensity, and that 
the magnitude of this effect might be moderated by individuals' religion and/or religiosity.

Research focusing the effects of religious practices (eg, prayer) on pain, and on the mechanisms explaining the effects of these practices, is a critical, understudied, next step in this field of research. The findings from this research could inform both clinicians and the public about how religious practices may be used to cope more effectively with pain. Moreover, a comparison of the effects of $\mathrm{SH}, \mathrm{MM}$, and religious practices on pain experience and pain-related-outcomes, and understanding for whom these pain management practices work, may also inform the relative utility of these strategies for pain self-management ensuring their optimal implementation. This study seeks to address knowledge gaps in this area by comparing the immediate effects of SH, MM and religious practices on pain-related outcomes relative to a control condition, and assessing what individual baseline characteristics moderate the effects of $\mathrm{SH}, \mathrm{MM}$ and religious practices on pain-related outcomes.

\section{Study aims and hypotheses}

The primary aim of this study (aim 1) is to compare the immediate effects of $\mathrm{SH}, \mathrm{MM}$ and $\mathrm{CP}$, relative to a control group $(\mathrm{CN})$, for increasing pain tolerance and reducing pain intensity and pain-related stress, in response to experimental painful stimulation in a sample of healthy volunteers. Based on the research performed to date, reviewed above, we hypothesise that participants who listen to audio recordings that facilitate the use of one of the three coping responses- $\mathrm{SH}, \mathrm{MM}$ and $\mathrm{CP}-$ will evidence greater pain tolerance and lower levels of pain intensity and pain-related stress than participants in the $\mathrm{CN}$ condition. Although one previous experimental study has directly compared the effects of a 3-minute practise of $\mathrm{MM}$ and $\mathrm{SH}$ on acute pain, ${ }^{64}$ no research to date has directly compared all three (ie, SH, MM and CP). Thus, we did not have any hypotheses about possible betweenstrategy differences on pain outcomes. However, we do plan to evaluate possible between-group differences to examine this.

An exploratory aim of this study (aim 2) is to identify possible shared and unique predictors of response to the three treatment conditions. The possible predictors we plan to test include sex, age, religious affiliation, hypnotic suggestibility, baseline mindfulness, acceptance, pain-related beliefs, religiosity, trait spirituality, previous experience with $\mathrm{SH}, \mathrm{MM}$ and $\mathrm{CP}$, outcome expectancies and trait absorption. We will test for both shared and treatment-specific prediction effects for each of these variables on all three study outcomes (ie, pain tolerance, pain intensity and pain-related stress), assessed via three variables (ie, pain tolerance, pain intensity and pain-related stress that will be assessed by two psychophysiological indicators: heart rate variability (HRV) and cortisol level). The aim 2 hypotheses are to determine if: (a) the effects of $\mathrm{SH}$ on pain-related outcomes will be predicted by trait absorption, hypnotic suggestibility, outcome expectations

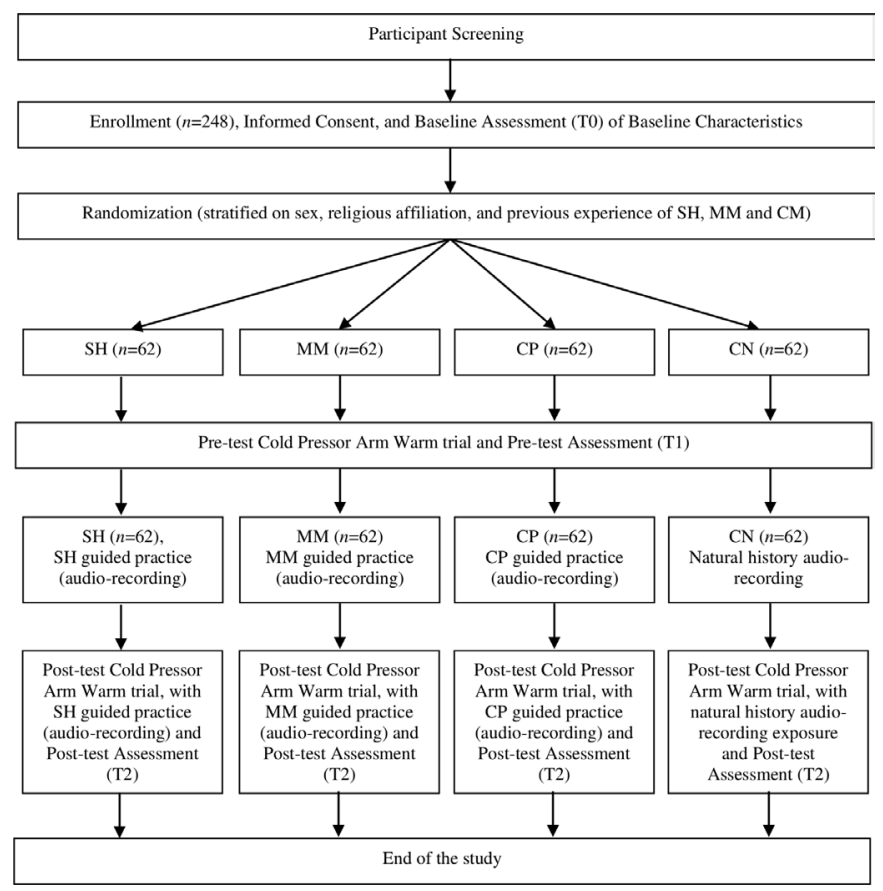

Figure 1 Flow of study procedures. CN, control group; MM, mindfulness meditation; $\mathrm{SH}$, self-hypnosis.

(OE), and previous experience of $\mathrm{SH}$; (b) the effects of MM on pain-related outcomes will be predicted by trait absorption, baseline mindfulness, acceptance, painrelated beliefs, catastrophising, $\mathrm{OE}$, and previous experience of MM; and that (c) the effects of CP on pain-related outcomes will be predicted by religious affiliation, S/R, trait absorption, acceptance, pain-related beliefs, catastrophising, OE, and previous experience of CP. Due to the large number of planned analyses (see the Statistical analysis plan section, described later), and because this is the first study to our knowledge that has compared these three approaches and evaluated treatment moderators in the same study, we view the tests of shared and unique predictors of outcome as exploratory.

\section{METHODS AND ANALYSIS \\ Study design}

The current study will use a randomised quantitative experimental mixed-design repeated-measures design. Figure 1 shows the overall flow of study procedures, while table 1 provides a brief structured summary of the study. This is a four-arm parallel prospective experimental controlled study, with one $\mathrm{CN}$ and three experimental conditions (SH, MM and CP), using the Cold Pressor Arm Wrap (CPAW) to induce pain. ${ }^{65}$ The effects of the treatment conditions on the three pain-related outcomes will be compared. All participants will be assessed at three assessment points: (a) baseline (T0) to assess baseline characteristics, pre-intervention (before randomised allocation and before the first CPAW trial); (b) pre-test (T1), pre-intervention, after randomised allocation and in response to the first CPAW trial; and (c) post-test (T2), 
Table 1 Structured summary of the study

\begin{tabular}{ll}
\hline Data category & Information $^{\mathbf{3 2}}$ \\
\hline $\begin{array}{l}\text { Registry and trial } \\
\text { identifying number }\end{array}$ & ClinicalTrials.gov (NCT04491630) \\
$\begin{array}{l}\text { Date of registration } \\
\text { in primary registry }\end{array}$ &
\end{tabular}

$\begin{array}{ll}\text { Source of funding } & \begin{array}{l}\text { Foundation BIAL Grant for Scientific } \\ \text { Research (grant number 188/18) }\end{array} \\ \text { Sponsor } & \text { William James Center for Research, } \\ & \text { ISPA-ISPA-University Institute }\end{array}$

Contact for public AFV, William James Center for

and scientific Research, ISPA-University Institute,

queries Rua Jardim do Tabaco, no. 34, 1149-

041 Lisbon, Portugal; +531969082988;

mafvalente@gmail.com

$\begin{array}{ll}\begin{array}{l}\text { Public and } \\ \text { scientific title }\end{array} & \begin{array}{l}\text { COping With PAin Through Hypnosis, } \\ \text { Mindfulness and Spirituality (COPAHS) }\end{array} \\ \begin{array}{l}\text { Countries of } \\ \text { recruitment }\end{array} & \text { Portugal }\end{array}$

Health condition(s) Healthy participants; experimentally or problem(s) induced acute pain

studied

$\begin{array}{ll}\text { Intervention(s) } & \text { Self-hypnosis; mindfulness meditation; } \\ & \text { Christian prayer; control }\end{array}$

Key inclusion and Inclusion criteria: (a)18 years old or exclusion criteria older; (b) read, speak and understand Portuguese; (c) willing to be randomly assigned to all four conditions

Exclusion criteria: (a) history of musculoskeletal problems, cancer, heart disease, stroke, epilepsy, diabetes or Raynaud syndrome; (b) open wound, cut or fracture in any of the upper limbs; (c) alcohol or substance dependence;

(d) cognitive or physical impairment, or severe psychopathology that could prevent participation

\begin{tabular}{|c|c|}
\hline \multirow[t]{5}{*}{ Study type } & Interventional \\
\hline & Allocation: randomised \\
\hline & Intervention model: parallel assignment \\
\hline & Masking: single blind \\
\hline & Primary purpose: basic science \\
\hline $\begin{array}{l}\text { (Anticipated) date } \\
\text { of first enrolment }\end{array}$ & November 20 \\
\hline Target sample size & 196 \\
\hline Recruitment status & $\begin{array}{l}\text { Study recruitment began on November } \\
20\end{array}$ \\
\hline \multirow[t]{2}{*}{ Primary outcome(s) } & Pain intensity \\
\hline & Pain tolerance \\
\hline $\begin{array}{l}\text { Key secondary } \\
\text { outcomes }\end{array}$ & Pain-related stress \\
\hline
\end{tabular}

immediately after the treatment condition procedures (ie, $\mathrm{SH}, \mathrm{MM}, \mathrm{CP}$ or $\mathrm{CN}$ ) and the second CPAW trial. The study results will be reported according to the Consolidated
Standards of Reporting Trials (CONSORT) guidelines for trials of non-pharmacological interventions. ${ }^{66}$

\section{Participants}

The participants will be a non-clinical sample of 196 healthy adult participants (approximately 50\% men). Sample size was determined using a priori power calculation using $\mathrm{G}^{*}$ Power (V.3.1), considering a mixed-design repeated-measures design, a default pre-post correlation across the pre-test and post-test of 0.5 , a small-to-medium effect size (Cohen's $f$ ) of 0.15 for a timexcondition interaction effect, a two-sided $\alpha$ of 0.05 and a power of 0.95 . Cohen's $f$ was set at 0.15 based on the results of previous research with both clinical and non-clinical populations supporting the anticipated small-to-large effects of CP $(0.34<f<0.43)$, SH $(0.15<f<0.37)$, and MM $(0.45<f<4.54)$ in pain intensity and tolerance. ${ }^{31} 3235385357$ We plan to enrol 248 participants in order to ensure a final sample size of 196 completers (49 per group), assuming a conservative $20 \%$ dropout rate.

Inclusion criteria are: (a) being at least 18 years old; (b) able to read, speak and understand Portuguese; and (c) willing to be randomly assigned to all four conditions (regardless of participant's own religious affiliation). Exclusion criteria include: (a) reporting history of musculoskeletal problems, cancer, heart disease, stroke, epilepsy, diabetes or Raynaud syndrome; (b) having an open wound, cut or fracture in any of the upper limbs; (c) self-reported alcohol or substance dependence; and (d) cognitive or physical impairment, or severe psychopathology that could prevent participation. ${ }^{15}$

\section{Study setting, recruitment, screening and enrolment}

This study will be conducted at the William James Center for Research, at ISPA-University Institute, Lisbon, Portugal (the host institution). All participants will be non-clinical healthy adults enrolled from the host institution internal and external participant pools. Procedures, such as informed consent, assessments, experimental trials and interventions, will be conducted in person and held at one of the host institution's labs.

Recruitment is anticipated to start in November 2020. Prospective participants will be sent an approach letter and contacted via telephone 1-2 weeks after mailing. Interested participants will be screened, during a telephone call, by research staff members to determine eligibility. Inclusion and exclusion criteria will be assessed via self-report, and reasons of ineligibility will be collected for purposes of adhering to the CONSORT standards. ${ }^{66}$

Prospective participants who are eligible and interested to participate will be invited to participate in an informed consent process that will be conducted in person by a research staff member. These participants will be given a full description of the study aims and procedures, as well as the opportunity to clarify any doubts or concerns. Participants will be assured of the confidential and voluntary nature of participation, and that they can discontinue participation at any moment. On agreement 
to participate, participants will then be asked to sign an informed consent form. Enrolled participants will complete baseline assessment (T0) in person.

Those individuals who decline to participate will be asked to provide a reason for their decline. They will also be asked basic demographic information-such as sex and age-to enable comparison between the study participants and eligible prospective participants who decline to participate.

\section{Randomisation, allocation and blinding}

After enrolment and baseline assessment, participants will be randomly assigned to one of the four conditions (SH, MM, CP or CN). Participants will be randomised in stratified blocks to ensure that subjects with each sex, religious affiliation, and previous experience in $\mathrm{SH}$, MM and CP have the same chance of being allocated to one of the four conditions. Randomisation process will be performed using a computerised random sequence generator.

Participants will be blind to the study hypotheses. During informed consent, in order to maximise the odds that participants will have similar outcome expectancies regarding the different experimental conditions, prospective participants will be told that they will listen to an audio recording that previous research studied as potentially helpful for pain management, and that the purpose of the study is to assess the effects of this audio recording on discomfort associated with the sensation of coldness. Participants will also be instructed not to disclose details of the content of the audios they receive to the experimenter. The experimenter who will conduct assessments and administer the audio-recorded interventions will be blind to both the condition to which subjects are assigned and the study hypotheses. The research staff member responsible for participants' randomisation will be blind to identifying information and to the code identifying each condition.

\section{Trial design}

Participants' baseline characteristics will be assessed at baseline (T0), immediately after consent process. Painrelated outcomes will be assessed both at pre-test assessment (T1) and post-test assessment (T2).

All participants will be provided a pre-test CPAW trial to allow for the pre-test (T1) assessment. The CPAW ${ }^{65}$ is an effective alternative approach to the traditional cold pressor test. ${ }^{15}$ It is a secure experimental method for inducing systemic stress and pain, involving attaching an arm wrap composed of MRI-safe gelpacs cooled to $1{ }^{\circ} \mathrm{C}-3^{\circ} \mathrm{C}$ to the forearm and hand of the individual. The CPAW has been shown to result in increases in post-test cortisol releases. ${ }^{65}$

Baseline cortisol level will be measured, and baseline HRV will be calculated based on a 5 min resting period before pre-test. The participants will have the cold arm wrap attached at $3^{\circ} \mathrm{C} \pm 0.5^{\circ} \mathrm{C}$ to the forearm and hand for as long as they tolerate the stimuli (maximum of $5 \mathrm{~min}$ ).
Pre-test (T1) assessment will be performed during (heart rate and pain tolerance) and after (salivary cortisol sample and pain intensity) the CPAW.

A second CPAW cycle will take place after a 20-minute rest interval, followed by a 20-minute interval during which participants will either listen to $\mathrm{SH}, \mathrm{MM}$, or CP induction/instruction or a natural history $(\mathrm{CN})$ audio recording, which has been previously validated as a control condition. ${ }^{67}$ This interval enables: the time for the exposure to $\mathrm{SH}, \mathrm{MM}$ or $\mathrm{CP}$; and to control for diffuse noxious inhibitory control. ${ }^{68}$ The second experiment-a second CPAW cycle lasting until subjects no longer tolerate the pain (up to a maximum of $5 \mathrm{~min}$ )—includes a post-test (T2) assessment similar to T1. Participants will also listen to a 5-minute recording of SH, MM, CP induction/instruction or a natural history audio recording (CN) during the second CPAW cycle.

\section{Experimental conditions/study interventions}

All of the interventions will be equivalent in terms of time and structure. All four will be presented via 20-minute audio-recordings just before the second CPAW cycle, which will teach them and allow them to practice the three active responses (SH, MM or $\mathrm{CP}$ ) or provide them with the control audio recording $(\mathrm{CN})$. Following this and during the second CPAW cycle, the participants in the active conditions will be invited to practise the strategy they were taught with the 20-minute audio recording, while also listening to a 5-minute recording to assist with this practice. The participants in the control condition will listen to a 5-minute natural history audio recording during the second CPAW cycle. All audio recordings will be audible only to the participant (ie, the researcher conducting the procedures will be blind to treatment condition).

To promote participant retention and adherence to intervention and assessments, a careful explanation of the study's potential social and academic relevance and benefits will be given to all participants during the consent process. Also, both the trials and assessments will be scheduled according to participants' preferences, and reminder telephone calls prior to the trial and assessments session will be made.

\section{Intervention content}

An in-depth description of the rationale for the selection of $\mathrm{SH}$ and $\mathrm{MM}$ is provided by Jensen, ${ }^{34}$ and by Williams et $a l^{41}$ Both $\mathrm{SH}$ and MM are well-established commonly used approaches that have evidence supporting their effectiveness with acute, chronic and experimentally induced pain. ${ }^{3436} \mathrm{CP}$, on the other hand, is one of the $\mathrm{S} / \mathrm{R}$ practices that has preliminary evidence supporting its effects on reducing pain. ${ }^{59}$

Specific scripts for each intervention will be developed based on theoretical and empirical foundations. Scripts for $\mathrm{SH}$ and MM will be developed by research team members (MJ and MD, respectively) who are experts in each of these interventions as applied to pain management. These scripts 
will then be translated, adapted into Portuguese, by two independent bilingual translators and back translated by a third independent bilingual translator. Any discrepancies in the translation will be resolved during a meeting of experts in these psychological interventions and pain management. A final version will be obtained through a consensus of these experts. The back-translation of the final version of the scripts will be reviewed and approved by $\mathrm{MJ}$ and $\mathrm{MD}$ to ensure that the content of the scripts is as originally intended. To ensure that the individuals in our population understand these scripts, a pilot test will be held in a sample of 10 Portuguese adults. Scripts for $\mathrm{CP}$ will be adapted from the existing online biblical meditations from the Society of Jesus (www.passoa-rezar.net), by a research team member (AF-V) which will closely collaborate on the CP script adaptation with a Portuguese CP expert from the Society of Jesus.

\section{SH condition}

After the 20-minute rest interval between the first cycle of CPAW and the second CPAW cycle, participants assigned to this condition will listen to a 20-minute recording with instructions of SH adapted from one of our team member's (MJ) proposed model. ${ }^{22}$ First, the audio recording will introduce and orient the participant to SH. Then instruction in SH will be provided, including: (a) how to self-induce a hypnotic induction; (b) specific self-suggestions for comfort and ability to manage intense sensations; and (c) posthypnotic suggestions that the participant will be easily able to use these hypnotic strategies on their own at a later time (ie, in this case, during the CPAW procedures that will follow). A second 5-minute audio-recording with instructions to guide the participant in $\mathrm{SH}$ will be provided during the second cycle of CPAW.

\section{MM condition}

After the 20-minute rest interval between the first cycle of CPAW and the second CPAW cycle, participants in the MM condition will listen to a 20-minute recording with instructions in the use and application of Vipassana $\mathrm{MM},{ }^{69}$ adapted from the manual developed by one of our team members (MD) ${ }^{70}$ First, the audio recording will focus on introducing the idea of attention to their breath, and of non-judgemental monitoring and acceptance of the all events and stimuli. Then a guided MM (body scan) experience will be provided. A second 5-minute audio recording with instructions to facilitate the MM (body scan) experience taught in the first audio recording will be provided during the second cycle of CPAW.

\section{CP condition}

After the 20-minute rest interval between the first cycle of CPAW and the second CPAW cycle, participants in this condition will listen to a 20-minute recording with $\mathrm{CP}$ instructions. These instructions will be adapted from the existing online biblical meditations from the Society of Jesus (www.passoa-rezar.net). First, the audio recording will introduce and orient the participant to CP. Then, a text of the New Testament of the Bible will be read two times, followed by a brief suggestion of prayer. A second 5-minute audio recording with instructions to facilitate the $\mathrm{CP}$ experience taught in the first audio recording, including the recording of a text of the Bible followed by a brief suggestion of meditation and relaxing music, will be provided during the second cycle of CPAW.

\section{CN condition}

Participants assigned to the control condition will participate in all of the assessments and experimental tasks, but will not be instructed to use any particular coping strategy to cope with the aversive stimulus provided by the CPAW procedure. After the rest interval between the first cycle of CPAW and the second CPAW cycle, participants in the $\mathrm{CN}$ condition will listen to a 20-minute natural history audio recording. ${ }^{67}$ The option for this recording is supported by: (a) previous research showing that individuals who were asked to listen to it found it to be a neutral, yet relaxing, passage; (b) the use of this passage as an effective control condition in previous studies. $^{71}{ }^{72}$ A 5-minute natural audio recording will be provided during the second cycle of CPAW.

\section{Study variables}

Table 2 provides a summary of the study variables and measures, as well as the assessment time points for each.

\section{Primary outcomes}

The primary outcome domains that will be assessed in this study are pain intensity and pain tolerance. These outcomes will be assessed both at pre-test (T1) and posttest (T2) assessment points.

\section{Secondary outcomes}

The secondary outcomes to be assessed are psychophysiological indicators of pain-related stress, as reflected by two domains: salivary cortisol level and HRV. These outcomes will be assessed both at pre-test (T1) and post-test (T2) assessment points.

\section{Other variables}

Other variables include presumed moderators of the effects of at least one intervention on primary and secondary outcomes, covariates that are thought to potentially bias or affect the effects of interventions on outcomes, descriptive and screening variables, and manipulation check variables.

\section{Predictors/moderators}

Predictor/moderator domains that will be assessed at baseline (T0) include hypnotic suggestibility, baseline mindfulness, acceptance, pain-related beliefs, religious affiliation, religiosity, trait spirituality, previous experience with $\mathrm{CP}, \mathrm{SH}$ and MM, outcome expectations and trait absorption.

\section{Covariates}

Sociodemographic variables that could influence outcomes (ie, sex and age) will be assessed at baseline (T0), immediately after consent process. 
Table 2 Assessment points, outcome variables and outcome measures

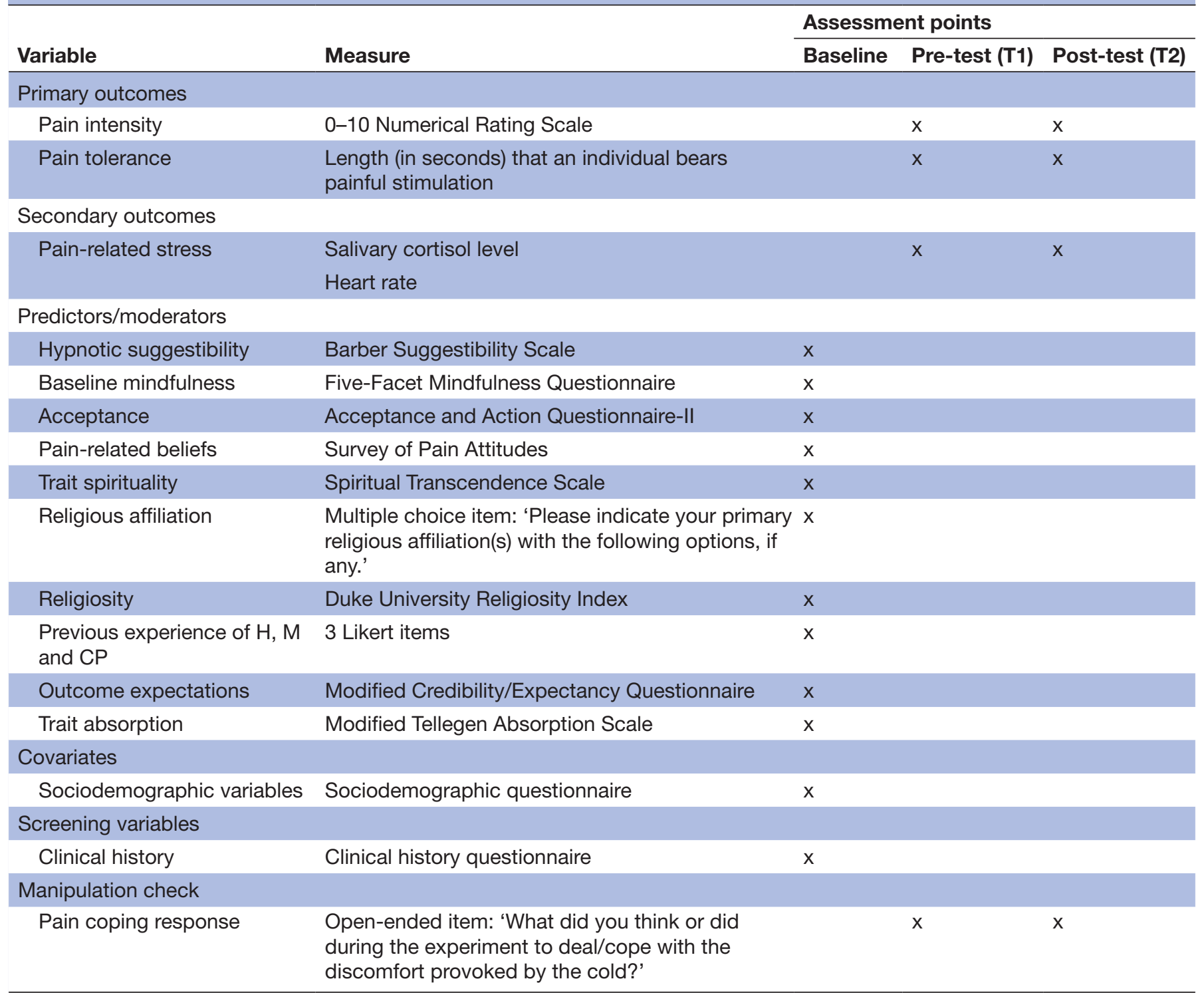

$\mathrm{CP}$, Christian prayer; $\mathrm{H}$, hypnosis; $\mathrm{M}$, meditation.

Descriptive and screening variables

Participants will be asked to provide clinical history information (the presence of any acute or chronic illness and/ or health condition, and which) both for determining eligibility and describing the sample. Additional demographic variables (listed in the Measures section) will also be assessed at this time to describe the sample.

\section{Manipulation check}

An open-ended question (regarding coping strategies employed during the CPAW trials to cope with experimentally induced pain) asked both at pre-test (T1) and post-test (T2).

\section{Assessment measures}

Primary outcome measures

To assess pain intensity, participants will be asked to rate their average pain intensity during the CPAW procedure using a 0-10 Numerical Rating Scale (NRS) of pain intensity, ${ }^{15}$ where 0 indicates 'No pain' and 10 indicates 'Worst imaginable pain'. Previous research supports the responsivity of the $0-10 \mathrm{NRS}$ as a measure of pain intensity. ${ }^{15}$ Pain tolerance will be operationalised as the length (in seconds) that an individual is willing to experience the aversive stimulation, up to a maximum of $5 \mathrm{~min}(300 \mathrm{~s})$. It will be timed by the research using a digital stopwatch.

\section{Secondary outcome measures}

Salivary cortisol level will be measured using the method and kits mentioned above and proposed by Schwabe et $a l^{73}$ Saliva samples will be collected immediately before and $20 \mathrm{~min} \pm 30 \mathrm{~s}$ after the CPAW. ${ }^{73}$ Salivary Cortisol Luminescence Immunoassay kits (ROCHE, 
Eletroquimioluminescence-Cobas), as well as a lab refrigerator to refrigerate the salivary cortisol samples, will be used.

\section{Heart rate will also be measured}

The recorded ECG will be treated according to the guidelines of BIOPAC Systems, in order to optimise the R-R interval data for HRV analysis (www.biopac.com). The existence of artefacts and ectopic beats will be monitored. The chosen measure of HRV is the high frequency power HRV, which is influenced by parasympathetic activity. An MP150 BIOPAC system using the software Acqknowledge V.4.0 (BIOPAC Systems) and HRV analysis (http:/ / kubios.uef.fi) will be used to measure heart rate and compute HRV and other time and frequency domains.

\section{Measures of predictors/moderators}

These will include the following:

\section{Hypnotic suggestibility}

Hypnotic suggestibility will be measured using the Barber Suggestibility Scale (BSS) ${ }^{7475}$ This scale entails eight test suggestions (arm lowering, arm levitation, hand lock, thirst hallucination, verbal inhibition, body immobility, post-hypnotic response and lastly selective amnesia) which are scored by the researcher: $1 / 2$ point if there are visible signs, and additional $1 / 2$ if the participant verbalises afterwards she/he became thirsty. The participants are also instructed to complete a subjective scoring booklet after the administration of the test suggestion, relative to the perceived experience with each suggestion. These items are answered in a 4-point type of Likert scale, from 0 ('Not light') to 3 ('Very light'). Objective scoring ranges from 0 to 8 , and the subjective score ranges from 0 to 24, with higher scores indicating higher levels of hypnotic suggestibility. The BSS can be applied with or without hypnotic induction. In this study it will be used as a standard audio-taped hypnotic induction, following the script recommend by the authors of the scale. ${ }^{74}$ The scale has shown both validity and reliability in different studies with both non-clinical and clinical samples. ${ }^{74} 75$

\section{Baseline mindfulness}

This will be assessed through the Portuguese version of the Five-Facet Mindfulness Questionnaire. ${ }^{76}$ This is a selfreport questionnaire composed of 39 items divided in five domains (observing, describing, acting with awareness, non-judging and non-reactivity), with higher scores indicating greater mindfulness capacities. The items are answered in a 5-point Likert scale, from 0 ('Never') to 4 ('Always'). Previous research supports the validity and reliability of both the original ${ }^{76}$ and Portuguese ${ }^{77}$ versions of the Five-Facet Mindfulness Questionnaire.

\section{Acceptance}

Acceptance will be measured by using a Portuguese modified version of the 7-item Acceptance and Action Questionnaire-II (AAQ-II). ${ }^{78}$ The items of the 7-item AAQ-II are answered in a 7-point type of Likert scale from 1 ('Never true') to 7 ('Always true') that assess a single domain of acceptance. Higher scores indicate higher degree of acceptance. Previous research supports the validity and reliability of the English and Portuguese versions of the AAQ-II. ${ }^{78} 79$

\section{Pain-related beliefs}

Pain-related beliefs will be assessed through the Portuguese version of the 35-item Survey of Pain Attitudes (SOPA-35). ${ }^{80}$ An official Portuguese version of the SOPA-35 is available from the publisher of the SOPA. The SOPA-35 is a 35-item self-report questionnaire assessing seven pain-related beliefs or domains: pain control, disability, medical cure, solicitude, medication, emotion and harm. Participants are asked to specify their degree of agreement with each statement in a Likert scale from 0 ('This is very untrue for me') to 4 ('This is very true for me'). Seven scores (one per pain-related belief) are computed, with higher scores indicating greater agreement with each belief. Previous research supports the validity and reliability of the original version of the SOPA$35{ }^{80}$ The study of the psychometric properties of the Portuguese SOPA-35 is in progress. ${ }^{81}$

\section{Trait spirituality}

The Spiritual Transcendence Scale (STS) will be used to assess spirituality as trait. The STS consists of 24 items divided into 3 domains: prayer fulfilment, universality and connectedness. ${ }^{82}$ Respondents are asked to rate their degree of agreement with each statement in a Likert scale, from 1 ('Completely disagree') to 5 ('Completely agree'). Previous research supports the validity and reliability of both the original ${ }^{82}$ and Portuguese ${ }^{83}$ versions of the STS.

\section{Religious affiliation}

To assess religious affiliation, participants will answer one multiple choice question ('Please indicate your primary religious affiliation among the following options, if any'). Participants will be asked to choose from a list of possible answers: Animist, Buddhist, Christian Anglican, Christian Baptist, Christian Calvinist, Christian Lutheran, Christian Orthodox, Christian Catholic, Other Christian, Hinduist, Islamic, Jewish, Shinto, Taoist, Other, Non-religious Agnostic, Non-religious Atheist, None of the previous options, Prefer not to answer.

\section{Religiosity}

The Duke University Religiosity Index (DUREL) is a 5-item measure that will be used to assess three major dimensions (corresponding the scale's three domains or subscales) of religious involvement: organisational religious activity, non-organisational religious activity, and intrinsic or subjective religiosity. ${ }^{84}$ Higher scores on the three subscales and on the total score of the measure indicate higher religiosity. The original version of this measure is a valid and reliable measure of religiosity. ${ }^{84}$ The study of the psychometric properties of the Portuguese version of DUREL is in progress. Preliminary findings indicate that 
the Portuguese version of DUREL is valid and reliable in a sample of Portuguese individuals with chronic pain. ${ }^{85}$

\section{Previous experience of $\mathrm{SH}, \mathrm{MM}$ and $\mathrm{CP}$}

To assess previous experience with $\mathrm{SH}, \mathrm{MM}$ and $\mathrm{CP}$, specifically, participants will be asked to first indicate (yes/no) if they have ever practised SH, MM or CP. If the answer is 'Yes,' they will then be asked to indicate how often they currently practise $\mathrm{SH}, \mathrm{MM}$ and $\mathrm{CP}$ in 3 Likert items developed by the research team, from 0 ('Rarely or never') to 4 ('More than once a day').

\section{Outcome expectations}

A modified version of the Credibility/Expectancy Questionnaire (CEQ) will be used to measure outcome expectations and rationale credibility relative to each of the interventions at the baseline. ${ }^{86}$ This measure consists of 6 type of Likert items divided into 2 domains-outcome expectations and rationale credibility. Previous research supports the validity and reliability of both the original version of the CEQ ${ }^{86}$ For the purpose of this study, the items of the CEQ will be adapted to fit the purposes and design of this study. The study of the psychometric properties of a Portuguese modified version of the CEQ will be performed in the context of this study.

\section{Trait absorption}

The Modified Tellegen Absorption Scale (MODTAS) will be used to assess trait absorption. ${ }^{87}$ This scale is composed of 34-item Likert (from 0-'never' to 4-'very often') divided into 5 domains (synesthesia, altered states of consciousness, aesthetic involvement, imaginative involvement, extra-sensory perception) that are grouped in a single second-order factor. Previous research supports the validity and reliability of the MODTAS. ${ }^{87} 88$

\section{Measures of covariates}

A sociodemographic questionnaire will be developed by the research team and will ask participants to provide, among others, information regarding their sex and age.

\section{Measures of descriptive and screening variables}

A clinical history questionnaire will be developed by the research team to assess variables needed to screen the participants' eligibility. This will consist of a list of different acute and chronic illnesses and/or health conditions. Participants will be asked to indicate the illnesses and/ or health conditions that they currently have. In addition, to collect information needed to describe the sample, the above-mentioned sociodemographic questionnaire will also ask participants to provide information regarding their education level, marital status, area of residence, employment status, household's income and religious denomination.

\section{Manipulation check}

To assess the coping strategies employed by participants to cope with the pain induced through CPAW, participants will answer one open-ended question ('What did you think or did during the experiment to deal/cope with the discomfort provoked by the cold?'). Participants will be presented this question and asked to provide their answer in writing. Answers will be coded by two independent researchers who will be blinded to the treatment condition, considering if $\mathrm{SH}, \mathrm{MM}, \mathrm{CP}$ or other coping strategy were used to cope with the pain.

\section{Assessment procedures}

All data collection procedures will be performed by a trained research assistant who is blind to the study hypotheses and to experimental condition. To maximise the quality of the self-report data, only one research assistant will obtain all measures, and this individual will be trained by a psychologist experienced in psychological questionnaire-based assessment.

\section{Adverse events and safety monitoring}

The findings from previous research indicate that unanticipated adverse effects associated with either the interventions, the CPAW procedures or the assessment procedures are unlikely. However, their occurrence will be closely monitored and recorded. For example, participants may experience fatigue while completing assessments at T0. Participants will also be told they are free to skip any questions and stop the assessment at time. Also, although participants will likely experience discomfort and pain during CPAW procedures (as these are what the procedures are designed to induce), they will be told that they can discontinue the CPAW procedures at any time for any reason they choose, and will also be instructed to take off the arm wrap if it feels too uncomfortable for them to continue. Given the short duration and minimal risks of this study, a formal data monitoring committee was deemed unnecessary.

\section{Statistical analysis plan}

Results will be considered statistically significant for a $\mathrm{p}$ value lower than 0.05 . Because data collection will be completed in person, we do not anticipate significant amounts of missing data. In the event that some data are missing, missing data analysis will be conducted to determine potential patterns in missing values or if missing values are random. Missing value replacement will be performed through the multiple imputation of Markov chain Monte Carlo method. ${ }^{89}$

For analysis of the qualitative data, participants' answers to the manipulation check open-ended question will be coded in accordance with a directed qualitative approach. ${ }^{90}$ An initial coding scheme will be developed a priori according to past research and used to categorise the units of analysis. Mutually exclusive emerging categories concerning the latent and manifest content of each pre-existing category ( $\mathrm{SH}, \mathrm{MM}, \mathrm{CP}$, other coping strategy) will be identified. The content excerpts (previously defined as unit of analysis) will be compared with the main a priori categories. Complementarily, inductive analysis will be conducted in units of analysis that do not 
fit the theoretically guided categories; for these, inductively created codes will be conceived.$^{91}$ Coding decisions will be assessed by comparing the answers' excerpts with the definitions of the categories and with other answers' excerpts within existing categories. The trustworthiness will be assured by the continued comparison in the coding process, focusing both theory-guided and inductively created categories, but also through the inter-rater reliability coefficient. Thus, at the end of the coding process, $10 \%$ of the questions randomly selected will be coded by the two independent researchers, trained in the coding matrix and blinded to the treatment condition (considering if SH, MM, CP or other coping strategy were used to cope with the pain). Inter-rater reliability (Cohen's kappa coefficient, $j$ ) will be computed, with a $j$ lower than 0 indicating no agreement, a $j$ between 0 and 0.20 indicating slight agreement, a $j$ between 0.21 and 0.40 indicating fair agreement, a $j$ between 0.41 and 0.60 indicating moderate agreement, and a $j$ between 0.61 and 0.80 or higher indicating, respectively, substantial or almost perfect agreement. ${ }^{92}$ The final coding of the participants' answers will be achieved by consensus. Categories will then be dummy coded, with 1 indicating that the participants used a given coping strategy and 0 indicating that participants did not use a certain coping strategy.

Descriptive statistics (ie, frequencies, percentages, means, SDs, as appropriate) will be computed to describe the sample and study variables at each assessment point. The distributions of the outcome data will also be evaluated (ie, by computing skewness and kurtosis) to determine if they meet criteria for the planned analyses. If they do not, the variables will be transformed (eg, using square root transformations) to normalise the data prior to analyses. Then, to test mean differences between four groups over the $\mathrm{T} 1$ and $\mathrm{T} 2$ assessment points, we will perform a series of mixed-design repeated-measures analyses of variance (ANOVAs), with the four pain-related outcomes as dependent variables, and sex, time of assessment (T1 and T2) and condition as independent variables. Effect size measures (partial eta squared) and statistical power $(1-\beta)$ will be computed and reported. If the study variables do not meet the assumptions for ANOVA analyses and cannot be transformed to meet those assumptions, we plan to employ the Wilcoxon test.

Secondary exploratory analyses will involve a series of hierarchical multiple regression analyses with the four outcome variables as the criterion measures, and experimental condition, predictor/moderator variables, time and their interactions as independent variables. We will examine both direct prediction effects (ie, the extent to which the predictor/moderator variables prospectively predict outcome across all of the treatment conditions) and moderator effects (ie, the extent to which the ability of the predictor/moderator variables to predict outcome varies as a function of treatment condition). All moderation analyses will consider the entire sample and will be done using PROCESS macro for IBM SPSS Statistics V.25. We will compute post-hoc correlation coefficients (continuous variables) or t-tests (dichotomous variables) to help explain any statistically significant moderator (ie, Moderator X Condition) effects that emerge. Data analysis will be conducted using IBM SPSS Statistics V.25.

\section{Patient and public involvement}

The development of the research question and choice of the outcome measures took into consideration the findings from previous findings present in the literature regarding the experience of patients with chronic pain and regarding the effects of SH, MM, and spiritual and religious practices on pain-related outcomes in people with chronic pain. The study itself does not involve patients. Patients were not directly involved in the development of the design of the study. Patients will not be involved neither in the recruitment and conduction of the study, nor in the assessment of the burden of the interventions. Study results will be published in peerreviewed indexed journals and presented at pain international scientific meetings. A full report of the study results will also be made available at the funding agency website, which is open to the public and will be made available to study participants.

\section{ETHICS AND DISSEMINATION}

The present study was reviewed and approved by ISPAUniversity Institute's internal Ethics Committee for Research (ISPA-UI ECR) on 3rd December 2018 (reference I/010/12/2018). The study will be compliant with international ethical principles and guidelines for studies involving human subjects. Compliant with Helsinki Declaration and with national and European legislation and with the European Union (EU) General Data Protection Regulation (EU Regulation 2016/679 of 27th April 2016). Participants will read and sign an informed consent form for participation in the study and for data collection and storage. The informed consent form will include a detailed description of the study aims and procedures. Informed consent will be obtained prior to any data collection or study procedures. Participants will be encouraged to discuss any concerns, any questions raised will be addressed by the research team. Participants will be assured confidentiality and anonymity. Participants' decision to stop any procedures at any time will be honoured.

Data processing activities within the study will be carried out in accordance with the updated data protection rules as specified in the EU General Data Protection Regulation which replaces the Data Protection Directive 95/46/EC. Identifiable information (II) will be linked to a unique study participant's ID. II and the key linking the participant ID to the former will be stored in a passwordprotected database, accessible only to the research team and staff members. Study data will be coded with the participant ID and stored in a password-protected computer database. Study data will be accessible only to the research team members. 
Any modification to the study protocol will be submitted to review and approval of ISPA-UI ECR. Study findings will be published in peer-reviewed indexed journals and presented at pain international scientific meetings.

\section{Twitter Alexandra Ferreira-Valente @Alexand79646363}

Acknowledgements The authors gratefully acknowledge the William James Center for Research (UIDB/04810/2020).

Contributors AF-V conceived the study idea, and together with FP and RC, developed the design of the study. MJ and MD, respectively, created the hypnosis and mindfulness meditation intervention manuals that will be employed to develop the intervention scripts and audio-recordings. MJ and JP-R substantially contributed to the review and refinement of the study design and protocol. AF-V planned the data analysis. All authors participated in the drafting of this manuscript and critically reviewed and approved the final version. AF-V, FP and RC will conduct the study procedures. AF-V is the principal investigator.

Funding This study was supported by a Foundation BIAL Grant for Scientific Research (grant number 188/18). AF-V has received a grant from the Portuguese Foundation for Science and Technology (grant number SFRH/BPD/121452/2016).

Disclaimer The funding agency had no role in the design of this study and will not have any role during its execution, analyses, interpretation of the data or decision to submit results.

\section{Competing interests None declared.}

Patient and public involvement Patients and/or the public were not involved in the design, or conduct, or reporting, or dissemination plans of this research.

\section{Patient consent for publication Not required.}

Provenance and peer review Not commissioned; externally peer reviewed.

Open access This is an open access article distributed in accordance with the Creative Commons Attribution Non Commercial (CC BY-NC 4.0) license, which permits others to distribute, remix, adapt, build upon this work non-commercially, and license their derivative works on different terms, provided the original work is properly cited, appropriate credit is given, any changes made indicated, and the use is non-commercial. See: http://creativecommons.org/licenses/by-nc/4.0/.

\section{ORCID iD}

Alexandra Ferreira-Valente http://orcid.org/0000-0002-3684-5561

\section{REFERENCES}

1 Wierzbicka A. Is pain a human universal? A cross-linguistic and cross-cultural perspective on pain. Emotion Review 2012;4:307-17.

2 Hall JE. Guyton and HAL textbook of medical physiology. 12th edn. Philadelphia, PA: Saunders, Elsevier, 2011.

3 Melzack R, Wall PD. Pain mechanisms: a new theory. Science 1965;150:971-8.

4 Merskey H, Bogduk N, eds. Classification of chronic pain: descriptions of chronic pain syndromes and definitions of pain terms. 2nd edn. Seattle: IASP Press, 1994

5 Grace PM, Hutchinson MR, Maier SF, et al. Pathological pain and the neuroimmune interface. Nat Rev Immunol 2014;14:217-31.

6 Melzack R, Wall P. The challenge of pain. New York: Basic Books, 1982.

7 Turk D, Okifuji A. Pain terms and taxonomies of pain. In: Ballantyne J, Fishman S, Rathmell J, eds. Bonica's management of pain. 5th edn. Philadelphia: Lippincott Williams Wilkins, 2019: 11-23.

8 van Rysewyk SP. A call for study on the meanings of pain. In: Meanings of pain. New York: Springer Berlin Heidelberg, 2016: 1-22.

9 Cordell WH, Keene KK, Giles BK, et al. The high prevalence of pain in emergency medical care. Am J Emerg Med 2002;20:165-9.

10 Sinatra R. Causes and consequences of inadequate management of acute pain. Pain Med 2010;11:1859-71.

11 Guru V, Dubinsky I. The patient vs. caregiver perception of acute pain in the emergency department. J Emerg Med 2000;18:7-12.

12 Todd KH, Ducharme J, Choiniere M, et al. Pain in the emergency department: results of the pain and emergency medicine initiative (PEMI) multicenter study. J Pain 2007;8:460-6.

13 Gouveia M, Augusto M. Custos indirectos dA DOR crónica em Portugal. rev Port Saúde Pública. Julho de 2011;29:100-7.

14 Baratta JL, Schwenk ES, Viscusi ER. Clinical consequences of inadequate pain relief: barriers to optimal pain management. Plast Reconstr Surg 2014;134:15S-21.
15 Ferreira-Valente MA, Pais-Ribeiro JL, Jensen MP. Validity of four pain intensity rating scales. Pain 2011;152:2399-404.

16 Ferreira-Valente A, Mendoza ME. Pain: From theory to clinical practice in health psychology. In: Leal I, Pais Ribeiro JL, eds. Manual of health psychology. Lisbon: Pactor Editora, 2009.

17 Cunningham NR, Kashikar-Zuck S, Coghill RC. Brain mechanisms impacted by psychological therapies for pain: identifying targets for optimization of treatment effects. Pain Rep 2019;4:e767.

18 Edwards RR, Dworkin RH, Sullivan MD, et al. The role of psychosocial processes in the development and maintenance of chronic pain. J Pain 2016;17:T70-92.

19 Ferreira-Valente A, Damião C, Pais-Ribeiro J. The role of spirituality in pain, function, and coping in individuals with chronic pain. Pain Med https://academic.oup.com/painmedicine/advance-article/doi/10. 1093/pm/pnz092/5482550

20 Ferreira-Valente A, Sharma S, Torres S. Does religiosity/spirituality play a role in function, pain-related beliefs, and coping in patients with chronic pain? A systematic review. J Relig Health http://link. springer.com/10.1007/s10943-019-00914-7

21 Fillingim RB. Individual differences in pain: understanding the mosaic that makes pain personal. Pain 2017;158:S11-18.

22 Jensen MP. Hypnosis for chronic pain management. New York: Oxford, 2011.

23 Kucyi A, Davis KD. The dynamic pain connectome. Trends Neurosci 2015;38:86-95

24 Meints SM, Edwards RR. Evaluating psychosocial contributions to chronic pain outcomes. Prog Neuropsychopharmacol Biol Psychiatry 2018;87:168-82.

25 Sharma S, Ferreira-Valente A, de C Williams AC, et al. Group differences between countries and between languages in painrelated beliefs, coping, and Catastrophizing in chronic pain: a systematic review. Pain Med 2020;21:1847-62.

26 Morley S, Williams A. New developments in the psychological management of chronic pain. Can J Psychiatry 2015;60:168-75.

27 Turk DC, Swanson KS, Tunks ER. Psychological approaches in the treatment of chronic pain patients: When pills, scalpels, and needles are not enough. Can J Psychiatry 2008;53:213-23.

28 Williams AC de C, Eccleston C, Morley S. Psychological therapies for the management of chronic pain (excluding headache) in adults. Cochrane pain, palliative and supportive care group. Cochrane Database Syst Rev http://doi.wiley.com/10.1002/14651858. CD007407.pub3

29 Interagency pain research coordinating Committee and National Institutes of health. Federal Pain Res Strat 2017 https://www.iprcc. nih.gov/sites/default/files/iprcc/FPRS_Research_Recommendations Final_508C.pdf

30 Adachi T, Fujino H, Nakae A, et al. A meta-analysis of hypnosis for chronic pain problems: a comparison between hypnosis, standard care, and other psychological interventions. Int J Clin Exp Hypn 2014;62:1-28.

31 Ardigo S, Herrmann FR, Moret V, et al. Hypnosis can reduce pain in hospitalized older patients: a randomized controlled study. BMC Geriatr 2016;16:14

32 Enea V, Dafinoiu I, Opris D, et al. Effects of hypnotic analgesia and virtual reality on the reduction of experimental pain among high and low hypnotizables. Int J Clin Exp Hypn 2014;62:360-77.

33 Hilton L, Hempel S, Ewing BA, et al. Mindfulness meditation for chronic pain: systematic review and meta-analysis. Ann Behav Med 2017;51:199-213.

34 Jensen MP. Psychosocial approaches to pain management: an organizational framework. Pain 2011;152:717-25.

35 Liu X, Wang S, Chang S, et al. Effect of brief mindfulness intervention on tolerance and distress of pain induced by cold-pressor task. Stress Health 2013;29:199-204

36 McClintock AS, McCarrick SM, Garland EL, et al. Brief mindfulnessbased interventions for acute and chronic pain: a systematic review. J Altern Complement Med 2019;25:265-78.

37 Reiner K, Tibi L, Lipsitz JD. Do mindfulness-based interventions reduce pain intensity? A critical review of the literature. Pain Med 2013:14:230-42.

38 Thompson T, Terhune DB, Oram C, et al. The effectiveness of hypnosis for pain relief: a systematic review and meta-analysis of 85 controlled experimental trials. Neurosci Biobehav Rev 2019:99:298-310.

39 Veehof MM, Trompetter HR, Bohlmeijer ET, et al. Acceptance- and mindfulness-based interventions for the treatment of chronic pain: a meta-analytic review. Cogn Behav Ther 2016;45:5-31.

40 Zeidan F, Vago DR. Mindfulness meditation-based pain relief: a mechanistic account: mechanisms supporting mindfulness-based analgesia. Ann N Y ACAD SCI 2016;1373:114-27. 
41 Williams RM, Ehde DM, Day M, et al. The chronic pain skills study: protocol for a randomized controlled trial comparing hypnosis, mindfulness meditation and pain education in veterans. Contemp Clin Trials 2020:90:105935.

42 Benham G, Woody EZ, Wilson KS, et al. Expect the unexpected: ability, attitude, and responsiveness to hypnosis. J Pers Soc Psychol 2006;91:342-50.

43 Jensen MP, Adachi T, Tomé-Pires C, et al. Mechanisms of Hypnosis: Toward the Development of a Biopsychosocial Model. Int J Clin Exp Hypn 2015;63:34-75.

44 Kober H, Buhle J, Weber J, et al. Let it be: mindful acceptance downregulates pain and negative emotion. Soc Cogn Affect Neurosci 2019;14:1147-58.

45 Tang Y-Y, Hölzel BK, Posner MI. Traits and states in mindfulness meditation. Nat Rev Neurosci 2016;17:59.

46 Day MA, Thorn BE, Ehde DM, et al. Moderators of mindfulness meditation, cognitive therapy, and Mindfulness-Based cognitive therapy for chronic low back pain: a test of the limit, activate, and enhance model. J Pain 2020;21:161-9.

47 Rippentrop EA, Altmaier EM, Chen JJ, et al. The relationship between religion/spirituality and physical health, mental health, and pain in a chronic pain population. Pain 2005;116:311-21.

48 Wachholtz $A B$, Pearce MJ, Koenig $\mathrm{H}$. Exploring the relationship between spirituality, coping, and pain. J Behav Med 2007;30:311-8.

49 Wachholtz AB, Pearce MJ. Does spirituality as a coping mechanism help or hinder coping with chronic pain? Curr Pain Headache Rep 2009;13:127-32.

50 Nelson JM. Religion, spirituality, and physical health. In: Nelson JM, ed. Psychology, religion and spirituality. New York: Springer, 2009: 311-45. https://link.springer.com/chapter/

51 Smothers ZPW, Koenig HG. Spiritual interventions in veterans with PTSD: a systematic review. J Relig Health 2018;57:2033-48.

52 Gonçalves JPdeB, Lucchetti G, Menezes PR, et al. Complementary religious and spiritual interventions in physical health and quality of life: a systematic review of randomized controlled clinical trials. PLoS One 2017;12:e0186539.

53 Tajadini H, Zangiabadi N, Divsalar K, et al. Effect of prayer on intensity of migraine headache: a randomized clinical trial. J Evid based complement Altern Med. Janeiro de 2017:22:37-40.

54 Wachholtz AB, Malone CD, Pargament KI. Effect of different meditation types on migraine headache medication use. Behav Med 2017:43:1-8

55 Wachholtz A, Vohra R, Metzger A. A reanalysis of a randomized trial on meditation for migraine headaches: distraction is not enough but meditation takes time. Complement Ther Med 2019;46:136-43.

56 Wachholtz AB, Pargament KI. Migraines and meditation: does spirituality matter? J Behav Med 2008;31:351-66.

57 Wiech K, Farias M, Kahane G, et al. An fMRI study measuring analgesia enhanced by religion as a belief system. Pain 2008;139:467-76.

58 Aldwin CM, Park CL, Jeong Y-J, et al. Differing pathways between religiousness, spirituality, and health: a self-regulation perspective. Psycholog Relig Spiritual 2014:6:9-21.

59 Aktaș YY, Karabulut N. A cross sectional study on complementary and alternative medicine use among a sample of Turkish Hospital outpatients with chronic lower back pain. Eur J Integr Med 2017;16:33-8.

60 Dezutter J, Wachholtz A, Corveleyn J. Prayer and pain: the mediating role of positive re-appraisal. J Behav Med 2011;34:542-9.

61 Jim HSL, Pustejovsky JE, Park CL, et al. Religion, spirituality, and physical health in cancer patients: a meta-analysis. Cancer 2015;121:3760-8.

62 Glover-Graf NM, Marini I, Baker J, et al. Religious and spiritual beliefs and practices of persons with chronic pain. Rehabil Couns Bull 2007;51:21-33

63 Wachholtz AB, Pargament KI. Is spirituality a critical ingredient of meditation? comparing the effects of spiritual meditation, secular meditation, and relaxation on spiritual, psychological, cardiac, and pain outcomes. J Behav Med 2005;28:369-84.

64 Swain NR, Trevena J. A comparison of therapist-present or therapistfree delivery of very brief mindfulness and hypnosis for acute experimental pain 2014;43:8.

65 Porcelli AJ. An alternative to the traditional cold pressor test: the cold pressor arm wrap. J Vis Exp 2014;83:e50849.

66 Boutron I, Moher D, Altman DG, et al. Extending the CONSORT statement to randomized trials of nonpharmacologic treatment: explanation and elaboration. Ann Intern Med 2008;148:295.
67 White G. Natural history of antiquities of Selborne. London: Cassel and Company, 1908.

68 Alabas OA, Tashani OA, Tabasam G, et al. Gender role affects experimental pain responses: a systematic review with metaanalysis. Eur J Pain 2012;16:1211-23.

69 Kabat-Zinn J, Living FC. Using the wisdom of your body and mind to face stress, pain, and illness. New York: Delacourt, 1990.

70 Day M. Mindfulness-Based cognitive therapy for chronic pain: a clinical manual and guide. Chichester: John Wiley \& Sons, Ltd, 2017.

71 Cropley M, Ussher M, Charitou E. Acute effects of a guided relaxation routine (body scan) on tobacco withdrawal symptoms and cravings in abstinent smokers. Addiction 2007;102:989-93.

72 Ussher M, Spatz A, Copland C, et al. Immediate effects of a brief mindfulness-based body scan on patients with chronic pain. J Behav Med 2014;37:127-34.

73 Schwabe L, Haddad L, Schachinger H. HPA axis activation by a socially evaluated cold-pressor test. Psychoneuroendocrinology 2008;33:890-5.

74 Barber TX, Wilson SC. The barber Suggestibility scale and the creative imagination scale: experimental and clinical applications. Am $J$ Clin Hypn 1978;21:84-108.

75 Pellicer Asensio X, Fusté Escolano A, Ruiz Rodríguez J. Psychometric analysis of the barber Suggestibility scale in a clinical population. Am J Clin Hypn 2018;60:386-402.

76 Baer RA, Smith GT, Hopkins J, et al. Using self-report assessment methods to explore facets of mindfulness. Assessment 2006;13:27-45.

77 Gregório S. Facetas de mindfulness: características psicométricas de Um instrumento de avaliação. Psychologica 2011;54:259-80.

78 Bond FW, Hayes SC, Baer RA, et al. Preliminary psychometric properties of the acceptance and action Questionnaire-II: a revised measure of psychological inflexibility and experiential avoidance. Behav Ther 2011;42:676-88.

79 Pinto-Gouveia J, Gregório S, Dinis A, et al. Experiential avoidance in clinical and non-clinical samples: AAQ-II Portuguese version. Int J Psychol 2012;18.

80 Jensen MP, Turner JA, Romano JM. Pain belief assessment: a comparison of the short and long versions of the surgery of pain attitudes. J Pain 2000;1:138-50.

81 Ferreira-Valente A, Garcia IQ, Rosa AM, et al. The Portuguese 35item survey of pain attitudes applied to Portuguese women with endometriosis. Scand J Pain 2019;19:553-63.

82 Piedmont R. Assessment of spirituality and religious sentiments: technical manual. Baltimore, 2004.

83 Góis S. Transcendência espiritual: Validação inicial da Spiritual Trancendence Scale na população portuguesa - Relação com as características da Personalidade. [online], 2016. Available: http://hdl. handle.net/10400.12/5262

84 Koenig HG, Büssing A. The Duke university religion index (DUREL): a Five-Item measure for use in Epidemological studies. Religions 2010;1:78-85.

85 Ferreira-Valente A, Pais-Ribeiro J, Jensen MP. Two Portuguese brief versions of religiosity measures applied in a sample of Portuguese patients with chronic pain. 12th Congress of the European pain Federation EFIC. Valencia, Spain, 2019.

86 Devilly GJ, Borkovec TD. Psychometric properties of the credibility/ expectancy questionnaire. 14, 2000.

87 Jamieson G. The modified Tellegen absorption scale: a clear window on the structure and meaning of absorption. Aust J Clin Exp Hypn 2005:33:119-39.

88 Lifshitz M, van Elk M, Luhrmann TM. Absorption and spiritual experience: a review of evidence and potential mechanisms. Conscious Cogn 2019;73:102760.

89 Jakobsen JC, Gluud C, Wetterslev J, et al. When and how should multiple imputation be used for handling missing data in randomised clinical trials - a practical guide with flowcharts. BMC Med Res Methodol 2017;17:162.

90 Assarroudi A, Heshmati Nabavi F, Armat MR, et al. Directed qualitative content analysis: the description and elaboration of its underpinning methods and data analysis process. $J$ Res Nurs 2018;23:42-55

91 Elo S, Kyngäs $\mathrm{H}$. The qualitative content analysis process. J Adv Nurs 2008;62:107-15.

92 Landis JR, Koch GG. The measurement of observer agreement for categorical data. Biometrics 1977;33:159. 